\title{
Critical Appraisal of Emergency Medicine Educational Research: The Best Publications of 2015
}

Corey R. Heitz, MD, Wendy Coates, MD, Susan E. Farrell, MD, EdM, Jonathan Fisher, MD, MPH, Amy Miller Juve, EdD, and Lalena M. Yarris, MD, MCR

\section{ABSTRACT}

Objective: The objectives were to critically appraise the medical education research literature of 2015 and review the highest-quality quantitative and qualitative examples.

Methods: A total of 434 emergency medicine (EM)-related articles were discovered upon a search of ERIC, PsychINFO, PubMED, and SCOPUS. These were both quantitative and qualitative in nature. All were screened by two of the authors using previously published exclusion criteria, and the remaining were appraised by all authors using a previously published scoring system. The highest scoring articles were then reviewed.

Results: Sixty-one manuscripts were scored, and 10 quantitative and two qualitative papers were the highest scoring and are reviewed and summarized in this article.

Conclusions: This installment in this critical appraisal series reviews 12 of the highest-quality EM-related medical education research manuscripts published in 2015.

$I^{\prime \prime 2}$ n 2012, the Academic Emergency Medicine consensus conference called for an increase in high-quality, hypothesis-driven education research. ${ }^{1}$ The intervening years have seen a growth in education research, as described in prior articles in this series. ${ }^{2-9}$ Highlighting this trend, beginning in 2017, Academic Emergency Medicine journal devoted an entire separate publication to emergency medicine educational research, Academic Emergency Medicine Education and Training (AEM EETT). ${ }^{10}$

Prior installments of this series were published in Academic Emergency Medicine Journal, ${ }^{2-9}$ using modifications of methodology for medical education literature review as described by the Alliance for Clinical Education for other specialties and based on that used for bench and clinical research. ${ }^{11,12}$ In this eighth installment of the annual critical appraisal series, reviewers have critically analyzed and ranked the emergency medicine (EM) education research from 2015. This article will highlight and summarize the most highly rated studies of 2015, which pertain to teaching and education in EM. Of note the focus is on research that advances the science of EM education, not necessarily research that uses education to affect patient care. Current trends in EM education research, as they can be inferred from this review, are summarized

From the Carilion Clinic/Nirginia Tech Carilion School of Medicine (CRH), Roanoke, VA; Harbor/University of California Los Angeles Medical Center (WC), Los Angeles, CA; Harvard Medical School (SEF), Boston, MA; Maricopa Medical Center/University of Arizona College of Medicine-Phoenix (JF), Phoenix, AZ; and Oregon Health \& Science University (AMJ, LMY), Portland, OR.

Received June 17, 2017; revision received August 24, 2017; accepted August 25, 2017

This article is being published simultaneously in Academic Emergency Medicine (AEM) and AEM Education and Training (AEM E\&T), both sponsored by the Society for Academic Emergency Medicine (SAEM). AEM DOI: https://doi.org/10.1111/acem.13305; AEM E\&T DOI: https://doi.org/10.1002/aet2.10063.

The authors have no relevant financial information or potential conflicts to disclose.

Supervising Editor: Sebastian Uijdehaage,PhD.

Address for correspondence and reprints: Lalena Yarris, MD, MCR; e-mail: yarris|@ohsu.edu

AEM EDUCATION AND TRAINING 2017;1:255-268. 
and compared to the previous year's trends. It is hoped that this article will serve as a valuable resource for EM educators and researchers invested in educational scholarship. ${ }^{13}$

\section{METHODS}

\section{Article Identification}

A medical librarian reproduced a previously used Boolean search strategy to identify all education research publications relevant to EM education. ${ }^{2}$ Medical subject heading $(\mathrm{MeSH})$ and keyword terms, including keyword variations to ensure completeness, were used. $\mathrm{MeSH}$ and keywords incorporated the following: emergency medicine and medical education, medical student, residents, continuing medical education, academic medical center and teaching hospital, to search MEDLINE through PubMed. Other databases searched included Scopus, Education Resources Information Center (ERIC), and PsychInfo. Publications were limited to English-language papers published in 2015. Searches were run in December 2015, January 2016, and February 2016.

\section{Inclusion and Exclusion Criteria}

We included publications relevant to the EM education of medical students, graduate medical education trainees, academic and nonacademic attending physicians, and other emergency providers. Relevant studies were defined as hypothesis-testing investigations, evaluations of educational interventions, or explorations of educational problems using either quantitative or qualitative methods. Publications were excluded if they were: 1) not considered to be peer-reviewed research (such as opinion pieces, commentaries, literature reviews, curricula descriptions without outcomes data); 2) not relevant to EM learners (such as reports on education of prehospital personnel, and international studies that could not be generalized to EM training outside of the country in which they were performed); 3) single-site survey studies; and 4) studies that examined outcomes limited to an expected learning effect without a comparison group.

\section{Data Collection}

One author reviewed and applied exclusion criteria to the 434 retrieved abstracts. Two authors independently screened and further refined the selection utilizing the exclusion criteria. Differences in opinion were resolved by discussion. Retrieved publications were maintained in a Microsoft Excel 2010 database. Sixty-one publications were made electronically available for all six reviewers to score independently.

\section{Scoring}

Scoring was based on a previously adapted version ${ }^{2,8,9}$ of the Research in Medical Education symposium of the Association of the American Medical Colleges ${ }^{11}$ and applying additional criteria from Alliance for Clinical Education study reviews. ${ }^{12}$ The scoring tool was iteratively modified in 2009 and 2010 to more accurately reflect EM education topics and the development of new areas of research including simulation and other technology. Each publication was assigned to a scoring system based on whether they were primarily quantitative or qualitative studies. Using accepted recommendations and hierarchical formulations, ${ }^{14-16}$ qualitative studies were assessed and scored in nine domains, parallel to those applied to the quantitative studies, for a maximum total score of 25 points. These also included the domains of measurement, data collection, and data analysis criteria, as defined specifically for high-quality qualitative research. The scoring criteria for both quantitative and qualitative research studies have been previously published in this review series and are represented in Tables 1 and 2.,5

It was decided a priori to include 10 quantitative and two qualitative articles, based on the large number reviewed. The top 10 articles from each author were compared. Articles that were in all authors' top 10 were included, as were articles that were in four of five (80\%) authors' top 10 lists. To reach 10 quantitative articles, this initial top 10 comparison was extended to the top 20. Authors recused themselves from reviewing articles in which they were coauthors.

Means and standard deviations (SDs) were calculated in Excel. Inter-rater reliability was assessed with intraclass correlation coefficient using a one-way random-effect model in SPSS 24.0.

\section{RESULTS}

A total of 434 papers and abstracts satisfied the search criteria, and 61 papers met the inclusion criteria. ${ }^{17-77}$ The authors scored these 61 manuscripts, and the 10 highest scoring quantitative $20,21,23,41,46,50-53,70$ and two qualitative articles ${ }^{18,60}$ are reviewed below, in alphabetical order by first author's last name. 
Table 1

EM Education Research Scoring Metrics: Quantitative Research

\begin{tabular}{|c|c|c|}
\hline Domain & Item Score & Maximum Domain Score \\
\hline Introduction: give 1 point for each criterion met & & 3 \\
\hline Appropriate description of background literature & 1 & \\
\hline Clear objective/hypothesis & 1 & \\
\hline Measurement: give 0 or 1 point for each criterion met & & 4 \\
\hline \multicolumn{3}{|l|}{ 1. Methodology } \\
\hline Has a posttest only & 1 & \\
\hline Has a pretest and posttest & 1 & \\
\hline \multicolumn{3}{|l|}{ 2. Groups } \\
\hline Both experimental and control group & 1 & \\
\hline Random assignment to groups & 1 & \\
\hline At least two institutions & 1 & \\
\hline More than two institutions & 1 & \\
\hline \multicolumn{3}{|l|}{ 2. Response rate } \\
\hline Response rate $<50 \%$ or not reported & 0 & \\
\hline Response rate $\geq 50 \%$ & 1 & \\
\hline Response rate $\geq 75 \%$ & 1 & \\
\hline Data analysis: give 0 or 1 point for each criterion met & & 3 \\
\hline \multicolumn{3}{|l|}{ 1. Appropriateness } \\
\hline Data analysis inappropriate for study design/type of data & 0 & \\
\hline Conclusion clearly addresses hypothesis/objective & 1 & \\
\hline Conclusions placed in context of literature & 1 & \\
\hline Limitations: assign a single best score & & 2 \\
\hline Limitations not identified accurately & 0 & \\
\hline Some limitations identified & 1 & \\
\hline Limitations well addressed & 2 & \\
\hline Innovation of project: assign a single best score & & 2 \\
\hline Previously described methods & 0 & \\
\hline New use for known assessment & 1 & \\
\hline New assessment methodology & 2 & \\
\hline Relevance of project: assign a single best score & & 2 \\
\hline Impractical to most programs & 0 & \\
\hline Relevant to some & 1 & \\
\hline Highly generalizable & 2 & \\
\hline Clarity of writing: assign a single best score & & 2 \\
\hline Unsatisfactory & 0 & \\
\hline Fair & 1 & \\
\hline Excellent & 2 & \\
\hline Total & & 25 \\
\hline
\end{tabular}


Table 2

EM Education Research Scoring Metrics: Qualitative Research

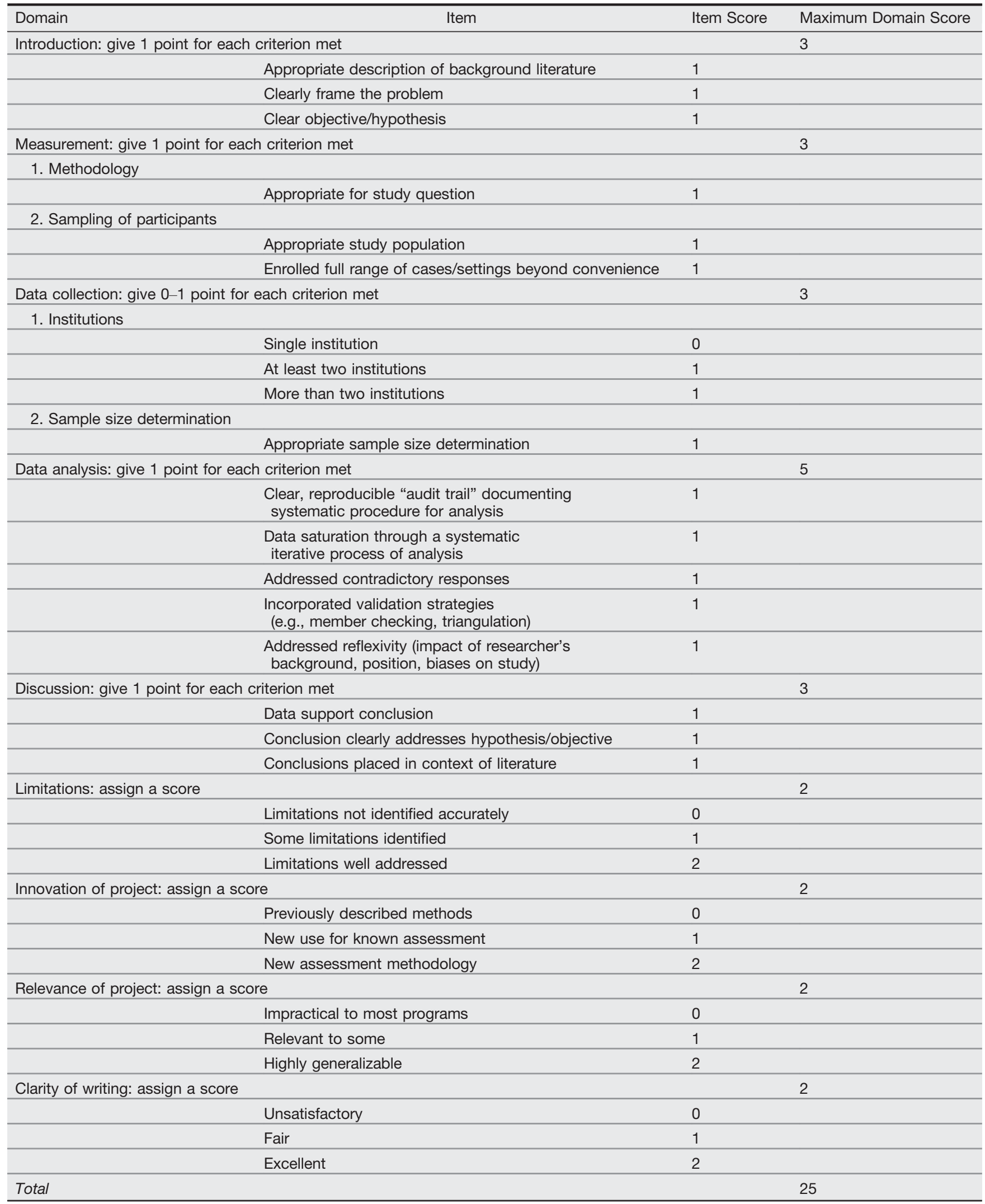

The range of reviewers' scores for the top articles was from 15 to 24 with a range of mean scores from 15.8 to 21.8 . SD of the scores of each article ranged from 0.5 to 3.4. Intraclass correlation coefficient revealed an average measure of 0.771 for all articles scored. 
Archambault, PM, Thanh, J, Blouin, D, et al. Emergency medicine residents' beliefs about contributing to an online collaborative slideshow. CJEM 2015;17:374-86.

Background: Collaborative writing applications (CWAs) may offer educational benefits to learners, such as knowledge retention, skill acquisition, and collaboration. This study explored Canadian EM residents' beliefs about their intent to contribute summaries of landmark articles to a collaborative slideshow while studying for a certification examination.

Methods: Participating residents were interviewed about the advantages/disadvantages, positive/negative referents and barriers/facilitators or contributing to a collaborative slideshow. Qualitative content analysis was used to identify salient beliefs.

Results: The dominant perceived benefit of contributing to the slideshow was learning consolidation, while information overload was the salient drawback. Writing the certification examination was a positive referent. The most common obstacle to participation was time constraints, while high-quality scientific information facilitated participation.

Strengths of this study: This study lends insight into how residents perceive the use of CWAs for educational benefits. The qualitative design is well suited to exploring an emerging phenomenon.

Relevance for future educational advancements: Knowledge of the barriers to participating in CWA learning may be of use to educators wishing to implement similar interventions. Further exploration of perceptions when CWAs are using for collaborative tasks versus learning would be of interest, as well as further study of the unique benefits of CWAs versus independent learning.

Beeson, MS, Holmboe, ES, Korte, RC, et al. Initial validity analysis of the emergency medicine milestones. Acad Emerg Med 2015;22:838-44.

Background: Emergency medicine milestones were developed by the Accreditation Council for Graduate Medicine Education (ACGME) as part of the Next Accreditation System. The EM milestones are used for resident assessment and program evaluation by measuring the acquisition of knowledge, skills, and abilities (KSAs) as an educational outcome. This study sought to measure the reliability and validity of the EM milestones

Methods: Observational study of all ACGME accredited EM programs ratings on all 23 milestone subcompetencies during a single discrete time period. Residents were grouped by postgraduate year (PGY) of training. Means and 95\% confidence intervals (CIs) were calculated for each PGY in aggregate and each individual subcompetency. Internal consistency was measured using a standardized Cronbach's alpha coefficient.

Results: A total of 5,805 residents from 162 EM programs were evaluated on the milestones. The overall mean performance ratings using the aggregate of all subcompetency scores were $2.38(95 \% \mathrm{CI}=2.37-$ 2.39) for EM-1 residents, 4.34 (95\% CI $=4.32-4.35)$ for EM-2 residents, $5.95(95 \% \mathrm{CI}=5.94-5.96)$ for EM-3 residents, and $6.79(95 \% \mathrm{CI}=6.77-6.81)$ for EM-4 residents. The mean performance ratings demonstrated discrimination between residency years. The reliability (internal consistency) within each year of training had a Cronbach's alpha coefficient of 0.96 for each year.

Strengths of this study: The large and complete data set involving all EM milestones and EM residents is important to demonstrate internal validity the newly developed milestones. It examined the evaluations from over 150 residencies representing a wide variety of residents and faculty raters. The use of the American Board of Emergency Medicine as an independent authority adds legitimacy to the study. The tight grouping of the milestones for each year of training and the high Cronbach's alpha provide strong evidence of internal validity of the milestones.

Relevance for future educational advancements: Having validated measures of resident assessment is essential to examining educational outcomes and the field of educational research. This study establishes the internal validity of EM milestones and makes EM an example for other specialties. Other studies have been published specifically using EM milestones because of the strength of validation process. Further studies need to examine the external validity of the EM milestones.

Bentley, S, Mudan, G, Strother, C, Wong, N. Are live ultrasound models replaceable? Traditional versus simulated education module for FAST exam. West J Emerg Med 2015;16:818-22.

Background: Training in ultrasound (US) during undergraduate medical education is increasing. The use of US simulation has been suggested and shown to be feasible for some US training indications. Simulated models have been shown to be effective for skill acquisition, but limited data exist comparing the use of live models to simulation.

Methods: This was a prospective, blinded, controlled noninferiority study performed on fourth-year 
emergency medicine students on the EM clerkship. Students performed ACEP US questions as a pretest and were surveyed regarding comfort. All students received a lecture and hands-on demonstrations and practice sessions, with the control group using live volunteers to practice and the intervention group using an US simulator. An identical posttest and comfort survey was administered, in addition to a proctored objective structured clinical examination (OSCE). Outcomes included knowledge from pretest to posttest as well as OSCE results.

Results: Ninety-three students completed the study. Pre- and posttest scores were similar between groups, and both groups improved from pretesting to posttesting. All students reported increases in comfort levels, with no difference between groups. No significant difference was found between OSCE scores for each group.

Strengths of this study: The authors chose a noninferiority methodology with a prospective, controlled design. They used validated questions from the ACEP US question bank for their pre- and posttest, and outcomes were mulimodal (knowledge, skills, attitudes). This allows for high levels of generalizability, with the limitation that the US simulator may be an expensive purchase.

Relevance for future educational advancements: The use of US simulators is similar to the use of live models for US education for at least some indications. Further research can evaluate other indications, as well as investigate the ability of simulators to increase diagnostic capability (i.e., abnormal findings.)

Bhat, R, Takenaka, K, Levine, B, et al. Predictors of a top performer during emergency medicine residency. J Emerg Med 2015;49:505-12.

Background: The goal in applicant selection is to obtain the best residents. Prior literature has suggested that EM clerkship grades, letters of recommendation, medical school quality, the interview, and other factors are associated with resident success as measured by various metrics. Little multi-institutional data exist to guide program directors as to which preresidency factors are predictive of resident success.

Methods: This was a retrospective cohort of three most recent graduating classes from nine EM residencies. Predictor variables include residency application, interview scores, rank list position, and medical school rankings. The end-of-residency semiannual evaluation was used as the objective measure of residency performance. The top third of residents was determined using the sum of their total evaluation scores.
Results: Data from 277 residents from nine programs were analyzed. EM home rotation grade, away rotation grade, USMLE Step 1 score, interview score, AOA, standard letter of recommendation (SLOR) global assessment, SLOR competitiveness ranking, and more than publications/presentations were all statistically associated with higher resident performance measurements.

Strengths of this study: This was a multi-institutional assessment of preresidency variables and which predict resident success. Objective measurements of success were used, in addition to standardized forms of resident assessment and presidency variable scoring/ rating. These features make this a much more rigorous look at these factors than has been previously performed, and generalizability is high.

Relevance for future educational advancements: The authors used standardized assessments and outcomes measurements to define their variables. Further literature investigating predictive factors of success should strive for this type of rigor. Finding the perfect mix of qualities which predict success in a given program, however, will continue to be challenging.

Gorgas, DL, Greenberger, S, Bahner, DP, Way, DP. Teaching emotional intelligence: a control group study of a brief educational intervention for emergency medicine residents. West J Emerg Med 2015;16:899-906.

Background: High emotional intelligence (EI) is said to improve team functioning, communication, decision making, physician-patient interactions, and career longevity. The four primary EI skills include self-awareness, self-management, social awareness, and relationship management. This study sought to determine if a brief education intervention could improve residents' EI scores.

Methods: Residents were randomized, stratified by sex and training year, to intervention and control groups. Both groups completed the 10-item Hay 360 EI Quiz, a free sample of the Hay 360 Emotional Competence Inventory. The intervention group participated in a 2-hour didactic and case-based discussion focused on social perspective taking (SPT), one subskill of social awareness. The intervention group completed the 10-item Hay scale immediately following the session and all residents completed the survey 6 months later. All residents in the program continued to receive longitudinal feedback on interpersonal communications, as ACGME mandates. A four-way ANOVA (group, sex, program year, and time) calculation was performed to analyze residents' EI scores. 
Paired t-test compared score differences in the intervention group.

Results: Thirty-three of 36 (92\%) residents completed the study. Intervention group EI scores improved in a statistically significant manner between preintervention and 6 months postintervention. There was no statistically significant change in scores immediately after the intervention. There was no relationship between sex or training and EI score change.

Relevance for future educational advances: This study was conducted at one program and involved small study numbers, resulting in insufficient power to demonstrate a relationship between sex or training level and EI score. EI score determination was based on a significantly abridged version of the Hay 360 EI scale. Although the intervention focused on only one subskill (SPT) component of EI and all residents received regular feedback on communication skills, the intervention group demonstrated improved EI scores 6 months postintervention. These results indicate that this component of EI may be teachable. The relationship between focused, brief EI education and other components of training and residents' actual clinical practice is yet to be defined.

Strengths of the study: This study used a stratified randomized controlled pre- and postintervention to demonstrate a change in EI scores on an abridged, but validated scale of EI. The authors' analysis of factors that relate to EI score was based on existing conceptual frameworks.

Hoskote, SS, Khouli, H, Lanoix, R, et al. Simulation-based training for emergency medicine residents in sterile technique during central venous catheterization: impact on performance, policy, and outcomes. Acad Emerg Med 2015;22:81-7.

Background: Simulation-based training in sterile technique during central venous catheterization reduces the rate of central line-associated bloodstream infection (CLABSI). This study had two objectives: 1) demonstrate the effectiveness of individual simulation-based training in improving EM residents' performance of sterile technique and 2) compare rates of CLABSI in medical intensive care unit (MICU) patients based on whether central venous catheterization was performed by EM residents in the emergency department (ED; Group 1) or by internal medicine (IM) residents in the MICU (Group 2).

Methods: All EM residents underwent simulationbased training in sterile technique to a specified observer-completed checklist of proficiency. MICU patient data were reviewed and extracted based on CLABSI rate and the placement conditions of central venous catheters (CVCs): Group 1 versus Group 2, as well as individual patient characteristics. Scores for change in resident performance before and after simulation training were compared using Wilcoxon signed-rank test. CLABSI rates and patient characteristics in the two groups were compared.

Results: Seventy-six EM residents completed simulation-based training in sterile technique. Postintervention scores improved with statistical significance ( $p<0.01$ ) based on interobserver agreement (Cohen's kappa coefficient $=0.98$ ). A total of $184 \mathrm{CVCs}$ were placed under sterile technique by Group 1. A total of 1,270 CVCs were placed under sterile technique by Group 2. There was no difference in the rates of CLABSI between the two groups (EM vs. IM placed CVC): 1.02 versus 1.02 per 1000 catheter-days $(p=0.99)$.

Relevance for future educational advances: This study is limited by the lack of data on CLABSI rate of EDplaced CVC prior to the initiation of the education intervention, making any change in rate of CLABSI in ED-placed CVC difficult to specifically measure. In addition, the retention of sterile technique skills was not studied. The study demonstrates that EM procedural education can improve EM residents' skills to the point that they are comparable to those of other specialties. This has implications for EM training in skills and procedures that may traditionally be considered to only be within the purview of other specialties.

Strengths of the study: This study demonstrates the effectiveness of simulation-based training in EM residents' simulated and clinical performance, directly linked to important patient outcomes.

Jordan, J, Elder, J, Uijtdehaage, S, Coates, WC. Dual learning in an emergency medicine clerkship improves student performance. J Emerg Med 2016;50 (471-6):e1-2.

Background: As EM clerkships expand around the country, clerkship directors are trying out various methods of education, including lectures, bedside teaching, simulation, asynchronous/online learning, and others. Standardization of clerkship experience and curricula is challenging. Prior literature has shown that directing students to particular chief complaints is an effective method of standardizing a clerkship curriculum.

Methods: This was a prospective study in which students on individual clerkship months were sorted into 
dual learning or standard learning groups. All students completed a multiple-choice pretest and were directed to see patients representing 10 specific chief complaints. The dual learning group received didactic lectures regarding five of these chief complaints. All students were directed to readings and other education materials. A posttest was given at the end of the rotation.

Results: Fifty-one students had complete data. Pretest scores were similar between groups. The dual learning group increased their scores on the posttest, while the standard learning group did not. The covariate of "EM-bound" did not affect score improvement.

Strengths of this study: The study used a quasi-experimental design to investigate a curricular change. The pre- and posttests were previously validated with the faculty group. Numerous resources were provided to both the control and the dual learning groups. Variables that may have affected the improvement on the posttest were investigated.

Relevance for future educational advancements: The authors have shown that a rigorous study design can be used to investigate curricular changes. It continues to be unclear what the best method of clerkship education may be, but it appears that multimodal education is necessary. Students who were allowed to self-direct learning did not perform as well as those who got inperson, faculty-facilitated didactic sessions.

Kellogg, AR, Coute, RA, Garra, G. Diagnostic reasoning for ST-segment elevation myocardial infarction (STEMI) interpretation is preserved despite fatigue. J Grad Med Educ 2015;7:27-31.

Background: The negative effects of fatigue and night shift work include impaired memory, decreased alertness, diminished psychomotor skills, and increased medical errors. Night shifts are associated with high rates of motor vehicle collisions, surgical complications, and intubation errors. The study examines the impact of fatigue on diagnostic reasoning.

Methods: Prospective pretest-posttest design of EM residents' ability to correctly interpret electrocardiograms (ECGs) and activate the cardiac cath lab in the setting of STEMI. A test consisting of 10 ECGs with STEMI and STEMI mimics was created and validated on attendings. Various measures of fatigue and sleepiness were also measured. Diagnostic certainty/confidence was also measured. Residents were tested once during daytime and then again after a night shift.

Results: Twenty-three senior EM residents were tested. There was no significant difference in diagnostic accuracy or confidence between daytime and nighttime accuracy despite have significant difference on multiple measure of fatigue and sleepiness. Interestingly, during daytime testing residents still displayed evidence of fatigue and sleepiness on measurements.

Strengths of this study: Despite its small sample size, the study was multicenter using residents from different years and different centers. The use of well-validated measures of fatigue and sleepiness adds to the power of this study. However, the study may have been underpowered to detect the difference. A power calculation or sensitivity analysis would be helpful to understand the risk of a Type II error.

Relevance for future educational advancements: Understanding the impact of sleepiness and fatigue to education, errors, and safety are critical to developing strategize to minimize risk. The finding of fatigue and sleepiness even during the day should be of concern.

Kessler, CS, Tadisina, KK, Saks, M, et al. The 5Cs of consultation: training medical students to communicate effectively in the emergency department. J Emerg Med 2015;49:713-21.

Background: Effective communication is critical to providing safe and high-quality care of patients. Poor communication and/or lack of standard communication processes can lead to errors and worse outcomes. This study examined the impact of training in standardized consultation process on communication in a real-time environment.

Methods: A multicenter randomized controlled trial comparing live training, asynchronous training, or no training of medical students on an emergency medicine rotation. Eight centers participated. Student consults were observed in real time using checklists and rating scales.

Results: A total of 208 students were observed performing 603 consults. Students who received training either live or asynchronous performed better than untrained students. Additionally, there was no difference between live and asynchronous training in student performance.

Strengths of this study: The use of both a multicenter and a randomized, controlled design make the study extremely well designed. Measuring the outcome by direct observation using a checklist in real-time clinical care further enhances the validity of the study.

Relevance for future educational advancements: This study has two important findings for educators. First, communications skills and standardized tools like the 
5Cs can be taught. Given strong study design as described above these results are probably generalizable to other tools like IPASS and/or SBAR. Additionally, this study adds to the growing body of literature that standard asynchronous learning is as effective as live training. However, the impact of training on outcomes and error reduction still needs to be defined.

Kessler, D, Pusic, M, Chang, TP, et al. Impact of just-in-time and just-in-place simulation on intern success with infant lumbar puncture. Pediatrics 2015;135: e1237-46.

Background: Infant lumbar puncture (LP) is a procedural skill that is unlikely to be successfully achieved prior to internship. This study sought to assess the effectiveness of two educational simulation instructional designs (simulation-based training at the commencement of internship [bundle education] vs. bundle education plus coached, refresher just-in-time and just-in-place [JIPT] practice in the clinical setting) in effecting interns' infant LP success on first clinical attempt.

Methods: Pediatric and emergency medicine interns at 34 centers were prospectively enrolled in the study. Participants comprised two historical cohorts: Cohort A (2009-2010) received bundle education, Cohort B (2010-2012) received bundle education plus JIPT immediately before performing an infant LP. Selfreported data were collected at the time of the clinical procedure. Interns' first-attempt infant LP success rate, secondary procedural data, and participant and procedural characteristics were analyzed via two-sided t-test and chi-square test.

Results: A total of 1,319 interns were enrolled, resulting in 436 first infant LPs. There was no statistically significant difference in procedural success rate between the two cohorts based on the two education design strategies. Cohort $\mathrm{B}$ participants, having received JIPT, demonstrated greater use of analgesia, more early stylet removal, and a lower mean number of LP attempts.

Strengths of the study: This multicenter study demonstrated the use of a recognized theoretical framework for an education intervention, drawing on the expertise of educators across 34 sites. A power analysis supported the data collection numbers.

Relevance for future educational advances: The study was limited by several factors, including control of education strategies at the participating sites and iterative changes to the education strategy over time.
Outcome data were was based on self-report and the definition and interpretation of successful procedural performance. In addition, the authors note that over time, more interns had been exposed to simulationbased training in LP prior to entering postgraduate training, although this did not seem to affect the outcomes in Cohort B. This study demonstrates the challenges in teaching and sustaining successful performance of procedures that are infrequently performed in the clinical setting. The authors have expanded on prior studies of the use of simulation training for procedures by introducing follow-up, justin-time refresher training in the clinical setting. However, it remains to be seen what the optimal educational strategy is for maintaining performance competency for infrequently performed procedures.

Reddy, ST, Zegarek, MH, Fromme, HB, Ryan, MS, Schumann, SA, Harris, IB. Barriers and facilitators to effective feedback: a qualitative analysis of data from multispecialty resident focus groups. J Grad Med Educ 2015;7:214-9.

Background: Although feedback is critical in medical education, the literature suggests that inadequate feedback occurs. This study explored multispecialty residents' experiences with giving and receiving feedback to identify feedback barriers and facilitators.

Methods: Residents in anesthesiology, emergency medicine, obstetrics and gynecology, and surgery from three institutions were invited to participate in focus groups to explore their feedback experiences and identify feedback barriers and facilitators. A grounded theory approach and constant comparison analysis strategy were used.

Results: Feedback themes identified included teacher factors, learner factors, feedback process, feedback content, and educational context. Barriers included unapproachable attendings, time pressures, and discomfort giving negative feedback, while the main facilitator identified was learner engagement in the feedback process.

Strengths of this study: Despite continued attention to feedback research, educators still struggle to maintain a culture of meaningful feedback in medical education. This study's strengths include the exploratory method and inclusion of multispecialty residents from several institutions. The findings reinforce the importance of learner engagement in feedback.

Relevance for future educational advancements: The feedback themes and barriers identified are consistent with the literature, but highlighting that the major 
facilitator of effective feedback is learner engagement may help direct future research. Understanding how to effectively increase learner engagement will be key to improving feedback culture. Future study should also build upon what is known about learner perceptions of feedback to explore how to evaluate feedback effectiveness.

Thoma, B, Sanders, JL, Lin, M, Paterson, QS, Steeg, J, Chan, TM. The social media index: measuring the impact of emergency medicine and critical care websites. West J Emerg Med 2015;16:242-9.

Background: Emergency medicine and critical care blogs and podcasts are increasingly being used for educational purposes, but assessing the quality and impact of these resources is challenging. These authors developed the social media index (SMI) to allow learners to identify quality educational websites and facilitate scholarly credit for educators who develop social media-based instructional materials.

Methods: The SMI was developed using data from social media platforms. Three normalized formulas were tested for statistical robustness and assessed for 1) temporal stability using repeated measures and website age and 2) correlation with impact by applying it to emergency medicine/critical care (EMCC) journals and measuring the correlation with known journal impact metrics.

Results: The logarithmic version of the SMI containing four metrics (Google PageRanks, Alexa Ranks, Facebook Likes, and Twitter Followers) was most statistically robust, correlating with website age (Spearman $\mathrm{r}=0.372 ; \mathrm{p}<0.01)$ and repeated measures $(\mathrm{r}=0.929 ; \mathrm{p}<0.01)$. It also correlated with all impact metrics for EMCC journals except number of articles published.

Strengths of this study: This study addresses a question that is timely, relevant, and of use to both learners and educators. Although the SMI is derived from followership variables, which are a proxy for quality, it provides a method of quality and impact assessment where none previously existed. Furthermore, followership captures a similar concept to the current criterion standards for assessing quality in peer-reviewed journals.

Relevance for future educational advancements: Authors developing blogs or podcasts or publishing papers describing the impact of social media-based innovations may wish to calculate and include the SMI as one outcome measure. Future research should seek to further define quality in Web-based educational content and seek to understand the relationship between SMI and educational outcomes.

\section{DISCUSSION}

\section{Trends in Medical Education Research 2015}

In 2015, there was a sharp increase in the number of articles that met our a priori criteria for full review $(n=61)$ compared with $2014(n=25)$. Upon discovery of this surge, we verified that our search and inclusion criteria were unchanged, although we formally reviewed 10 papers that employed survey methodology in 2015 (compared to none in 2014). The rate of funding for studies this year increased slightly from $16 \%$ to $20 \%$. Reed et al. ${ }^{78}$ demonstrated that studies that were funded tended to be of higher quality when assessed on a validated tool. In 2015, 12 studies (20\%) were funded, one received federal funding, two received foundational funding, and eight received support from an institution or unspecified organization. $^{18,30,33,46,48,53-59,71,76}$ Four of the 12 highlighted articles (33\%) this year were funded research. ${ }^{18,46,53,60}$

Emergency medicine journals published $71 \%$ of this year's articles, including nine (75\%) of the highlighted articles. This represents an increase from last year when $56 \%$ of articles appeared in EM journals. Eleven (18\%) were published in medical education-focused journals including $17 \%$ of those highlighted, and the remaining seven (11\%) appeared in a variety of journals (anesthesia, pediatrics, simulation, trauma, and generalist). Almost all papers had at least one EM author (95\%), which is an increase from 2014 (84\%) but similar to 2013 (91\%). Of interest is the growth of representation from different global regions. While 42 (69\%) papers reported on studies conducted in the United States and five (8\%) in Canada, we noted five U.S./Canadian collaborations and nine papers with global origins (Australia, Brazil/United States, China [Hong Kong], France, Germany, Germany/Switzerland, Iran, New Zealand, and Thailand).

Experimental (hypothesis testing) studies declined in 2015 from $36 \%$ of the total to $15 \%$ of all reviewed studies. $^{30,33,41,46,50,52,57,64,76}$ Notably, four of these were articles highlighted for excellence $41,46,50,52$ and represent $15 \%$ of the featured studies. Six studies $(10 \%)$ involved qualitative methodology ${ }^{18,39,47,54,60,69}$ of which two were highlighted. ${ }^{18,60}$ There were 10 papers $(16 \%)$ that employed survey methodology but none met the criteria for a highlighted article. ${ }^{36,37,42,61 \text {, }}$ 63,65,67,74,75,77 The remaining 36 papers (59\%) were 


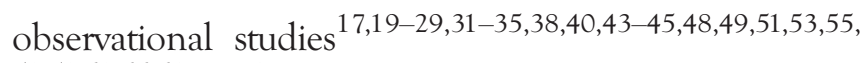
$58,59,62,66,68,70-73$ and accounted for $50 \%$ of the highlighted articles. ${ }^{20,21,23,51,53,70}$ It is interesting to note that each study design had representation in meeting the validated criteria to be a highlighted article, with the exception, this year, of survey methodology. In our quest as a specialty to perform high-quality research in medical education, we believe that it is important to have rigorous methodology and high-level outcomes. As outlined by Kirkpatrick and Kirkpatrick, ${ }^{79}$ the most desirable types of educational research studies measure the impact of a training program on modifying learner behavior in real settings and demonstrating independent improvement in metrics targeted by the intervention, such as a decrease in morbidity or an increase in compliance with a quality improvement metric. This year's study by Hoskote et al. ${ }^{46}$ is a good example of this principle. In general, lower Kirkpatrick-level studies that measure learner satisfaction or self-assessment were not likely to have met the criteria for the highlighted articles.

The study populations included medical students (36\%), ${ }^{19,21-23,33,35,36,38,42,44,45,47,50,52,53,55,66-68,72,73}$

residents $(54 \%), 17,18,20,24-29,31,34,37,39,40,43,46,48,49,53,57-$ $61,63,64,68,69,71,74,76$ and a variety of others (attending physicians, nurses, interprofessional teams, fellows, midlevel providers, paramedics, validity evidence, and department flow).

Studies that are conducted at multiple institutions are important since they demonstrate that the intervention is effective in a variety of settings and may be more generalizable to others who wish to implement a similar program. This year, 10 (16\%) studies were conducted at more than two sites. $17,20,23,37,43,44,52,53,62,70$ Researchers in EM can be more confident in the value of their interventions if they produce excellent results when applied to many different types of learners and taught by a variety of instructors. The authors of this piece advocate for the creation of multi-institutional collaborations to improve the overall quality of EM education research.

The topics of study this year had many similarities to previous years, in that technology $18,21,24-26,28,30-$

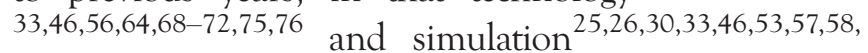
$64,71,72,75,76$ were prominent. Procedural learning and competency, with or without simulation as the focus, were studied in seven articles. ${ }^{21,24,28,31,46,53,76}$ The biggest gain in topic for study was assessment and competency, likely in an attempt for programs to meet stipulated benchmarks of the Next Accreditation
Table 3

Trends for the Reviewed Medical Education Research Articles Published in 2015

\begin{tabular}{lcc}
\hline Variable & $\begin{array}{c}\text { All Publications } \\
(n=61)\end{array}$ & $\begin{array}{c}\text { Highlighted } \\
(n=12)\end{array}$ \\
\hline Funding & 12 & 4 \\
\hline Learner groups & & \\
\hline Medical students & 22 & 4 \\
\hline Residents & 33 & 7 \\
\hline Faculty & 4 & 0 \\
\hline Other & 11 & 1 \\
\hline Study methodology & & \\
\hline Survey & 10 & 0 \\
\hline Observational & 36 & 6 \\
\hline Experimental & 9 & 4 \\
\hline Qualitative & 6 & 2 \\
\hline Topics of study & & 10 \\
\hline Assessment/competence & 40 & 4 \\
\hline Technology & 21 & 2 \\
\hline Simulation & 13 & 5 \\
\hline Communications & 13 & 0 \\
\hline Learner satisfaction & 12 & 3 \\
\hline Procedures & 7 & 3 \\
\hline Curriculum & 6 & \\
\hline (1) & & \\
\hline
\end{tabular}

*It is possible to exceed the total $n=61$ or $n=12$ in these categories due to multiple learner categories or study topics.

System. Forty articles (66\%) and $83 \%$ of the highlighted articles ${ }^{20,21,23,41,46,50-53,60}$ were in this broad category. As usual, some articles focused on pediatric topics. $^{25,33,53,56,77}$ The importance of communication was studied in 13 (21\%) of studies, marking a drastic increase over past years. ${ }^{18,26,39,41,47,49,52,54,59,60,66,70,77}$ The popularity of clinical reasoning studies waned this year with only two studies (3\%). ${ }^{51,68}$ A summary of the trends of articles published in 2015 is provided in Table 3.

\section{LIMITATIONS}

Despite rigorous searches repeated over several months of the English-language literature for all publications that met review criteria, these searches may have erroneously omitted high-quality studies. The exclusion criteria used may be considered overly rigorous. For example, we excluded single-site survey studies, as well as studies that demonstrated an "expected learning effect" without the inclusion of other learning outcomes. Although the rating metrics used in this analysis have been previously published and iteratively revised over several years, only limited validity evidence exists for the scoring methods. This may 
contribute to a ranking cut point of quality articles that may be too stringent. However, the aim of this continuing series is to review high-quality EM education research, and all revisions to the article scoring and selection process have been made to increase the relevance of the papers reviewed, as well as their potential to impact the educational practice of the reader.

\section{CONCLUSIONS}

This article presents a critical appraisal of high-quality educational research in emergency medicine. A great increase in articles scored occurred this year, and the 10 quantitative and two qualitative articles represent the most methodologically superior papers. As EM educators strive for higher-quality educational research, they can use these examples for guidance.

The authors acknowledge Gloria J. Kuhn, DO, PhD, Michelle Lin, MD, and Philip Shayne, MD, who helped develop the initial study concept and critical appraisal procedure for this work.

\section{References}

1. LaMantia J, Deiorio NM, Yarris LM. Executive summary: education research in emergency medicine: opportunities, challenges, and strategies for success. Acad Emerg Med 2012;19:1319-22.

2. Farrell SE, Coates WC, Khun GJ, Fisher J, Shayne P, Lin M. Highlights in emergency medicine medical education research: 2008. Acad Emerg Med 2009;16:1318-24.

3. Fisher J, Lin M, Coates WC, et al. Critical appraisal of emergency medicine educational research: the best publications of 2011. Acad Emerg Med 2013;20:200-8.

4. Shayne P, Coates WC, Farrell SE, et al. Critical appraisal of emergency medicine educational research: the best publications of 2010. Acad Emerg Med 2011;18:1081-9.

5. Lin M, Fisher J, Coates WC, et al. Critical appraisal of emergency medicine education research: the best publications of 2012. Acad Emerg Med 2014;21:322-33.

6. Farrell SE, Kuhn GJ, Coates WC, et al. Critical appraisal of emergency medicine education research: the best publications of 2013. Acad Emerg Med 2014;21:1274-83.

7. Yarris LM, Juve AM, Coates WC, et al. Critical appraisal of emergency medicine education research: the best publications of 2014. Acad Emerg Med 2015;22:1327-36.

8. Kuhn GJ, Shayne P, Coates WC, et al. Critical appraisal of emergency medicine educational research: the best publications of 2009. Acad Emerg Med 2010;17(Suppl 2):S16-25.

9. Shayne P, Coates WC, Farrell SE, et al. Critical appraisal of emergency medicine educational research: the best publications of 2010. Acad Emerg Med 2011;18:1081-9.
10. Kline JA, Promes SB. Introducing Academic Emergency Medicine Education and Training. Acad Emerg Med 2016;23:736-7.

11. Kogan JR. Review of medical education articles in internal medicine journals. Alliance for Clinical Education (ACE) Journal Watch. Teach Learn Med 2005;17:307-11.

12. Margo K, Chumley H. Review of medical education articles in family medicine journals. Journal Watch from ACE (Alliance for Clinical Education). Teach Learn Med 2006;18:82-6.

13. Boyer EL. The scholarship of teaching from: scholarship reconsidered: priorities of the professoriate. College Teach 1991;39:11-13.

14. Cote L, Turgeon J. Appraising qualitative research articles in medicine and medical education. Med Teach 2005;27:71-5.

15. Daley J, Willis K, Small R, et al. A hierarchy of evidence for assessing qualitative health research. J Clin Epidemiol 2007;60:43-9.

16. O’Brien BC, Harris IB, Beckman TJ, Reed DA, Cook DA. Standards for reporting qualitative research: a synthesis of recommendations. Acad Med 2014;89:1245-51.

17. Aldeen AZ, Quattromani EN, Williamson K, Hartman ND, Wheaton NB, Branzetti JB. Faculty prediction of intraining examination scores of emergency medicine residents: a multicenter study. J Emerg Med 2015;49:64-9.

18. Archambault PM, Thanh J, Blouin D, et al. Emergency medicine residents' beliefs about contributing to an online collaborative slideshow. CJEM 2015;17:374-86.

19. Askew KL, O'Neill JC, Hiestand B, Manthey DE. Combined versus detailed evaluation components in medical student global rating indexes. West J Emerg Med 2015;16:885-8.

20. Beeson MS, Holmboe ES, Korte RC, et al. Initial validity analysis of the emergency medicine milestones. Acad Emerg Med 2015;22:838-44.

21. Bentley S, Mudan G, Strother C, Wong N. Are live ultrasound models replaceable? Traditional versus simulated education module for FAST exam. West J Emerg Med 2015;16:818-22.

22. Bernard AW, Martin DR, Moseley MG, et al. The impact of medical student participation in emergency medicine patient care on departmental Press Ganey scores. West J Emerg Med 2015;16:830-8.

23. Bhat R, Takenaka K, Levine B, et al. Predictors of a top performer during emergency medicine residency. J Emerg Med 2015;49:505-12.

24. Blehar DJ, Barton B, Gaspari RJ. Learning curves in emergency ultrasound education. Acad Emerg Med 2015;22:574-82.

25. Bloch SA, Bloch AJ. Simulation training based on observation with minimal participation improves paediatric emergency medicine knowledge, skills and confidence. Emerg Med J 2015;32:195-202. 
26. Briggs A, Raja AS, Joyce MF, et al. The role of nontechnical skills in simulated trauma resuscitation. J Surg Educ 2015;72:732-9.

27. Burkhardt JC, Stansfield RB, Vohra T, Losman E, Turner-Lawrence D, Hopson LR. Prognostic value of the multiple mini-interview for emergency medicine residency performance. J Emerg Med 2015;49:196-202.

28. Carrié C, Biais M, Lafitte S, Grenier N, Revel P, Janvier G. Goal-directed ultrasound in emergency medicine: evaluation of a specific training program using an ultrasonic stethoscope. Eur J Emerg Med 2015;22:419-25.

29. Chakravarthy B, Posadas E, Ibrahim D, et al. Increasing off-service resident productivity while on their emergency department rotation using shift cards. J Emerg Med 2015;48:499-505.

30. Chan CH, Chan TN, Yuen MC, Tung WK. Evaluation of a simulation-based workshop on clinical performance for emergency physicians and nurses. World J Emerg Med 2015;6:16-22.

31. Chiem AT, Chan CH, Ander DS, Kobylivker AN, Manson WC. Comparison of expert and novice sonographers' performance in focused lung ultrasonography in dyspnea (FLUID) to diagnose patients with acute heart failure syndrome. Acad Emerg Med 2015;22:564-73.

32. Clinkscales JD, Fesmire FM, Hennings JR, Severance HW, Seaberg DC, Patil N. The effect of emergency medicine residents on clinical efficiency and staffing requirements. Acad Emerg Med 2016;23:78-82.

33. Couto TB, Farhat SC, Geis GL, Olsen O, Schvartsman C. High-fidelity simulation versus case-based discussion for teaching medical students in Brazil about pediatric emergencies. Clinics (Sao Paulo) 2015;70:393-9.

34. Dehon E, Jones J, Puskarich M, Sandifer JP, Sikes K. Use of emergency medicine milestones as items on end-of-shift evaluations results in overestimates of residents' proficiency level. J Grad Med Educ 2015;7:192-6.

35. Dehon E, McLemore G, McKenzie LK. Impact of trainees on length of stay in the emergency department at an academic medical center. South Med J 2015;108:245-8.

36. Dehon E, Cruse MH, Dawson B, Jackson-Williams L. Mentoring during medical school and match outcome among emergency medicine residents. West J Emerg Med 2015;16:927-30.

37. Doty CI, Roppolo LP, Asher S, et al. How do emergency medicine residency programs structure their clinical competency committees? A survey. Acad Emerg Med 2015;22:1351-4.

38. Feazel L, Block J, Jayawardena A, Wehr P, House H, Buresh C. Wilderness medicine race for preclinical students. Clin Teach 2016;13:271-6.

39. Flanigan M, Heilman JA, Johnson T, Yarris LM. Teaching and assessing ED handoffs: a qualitative study exploring resident, attending, and nurse perceptions. West J Emerg Med 2015;16:823-9.
40. Goldflam K, Bod J, Della-Giustina D, Tsyrulnik A. Emergency medicine residents consistently rate themselves higher than attending assessments on ACGME milestones. West J Emerg Med 2015;16:931-5.

41. Gorgas DL, Greenberger S, Bahner DP, Way DP. Teaching emotional intelligence: a control group study of a brief educational intervention for emergency medicine residents. West J Emerg Med 2015;16:899-906.

42. Hern HG, Wills CP, Johnson B. Change to an informal interview dress code improves residency applicant perceptions. West J Emerg Med 2015;16:127-32.

43. Hiller K, Miller ES, Lawson L, et al. Correlation of the NBME advanced clinical examination in EM and the national EM M4 exams. West J Emerg Med 2015;16:138-42.

44. Hiller K, House J, Lawson L, Poznanski S, Morrissey TK. Medical student performance on the National Board of Medical Examiners Emergency Medicine Advanced Clinical Examination and the National Emergency Medicine M4 Exams. West J Emerg Med 2015;16:919-22.

45. Hiller KM, Waterbrook A, Waters K. Timing of emergency medicine student evaluation does not affect scoring. J Emerg Med 2016;50:302-7.

46. Hoskote SS, Khouli H, Lanoix R, et al. Simulation-based training for emergency medicine residents in sterile technique during central venous catheterization: impact on performance, policy, and outcomes. Acad Emerg Med 2015;22:81-7.

47. House JB, Theyyunni N, Barnosky AR, et al. Understanding ethical dilemmas in the emergency department: views from medical students' essays. J Emerg Med 2015;48: 492-8.

48. Hurley KF, Giffin NA, Stewart SA, Bullock GB. Probing the effect of OSCE checklist length on inter-observer reliability and observer accuracy. Med Educ Online 2015;20:29242.

49. Isoardi J, Spencer L, Sinnott M, Eley R. Impact of formal teaching on medical documentation by interns in an emergency department in a Queensland teaching hospital. Emerg Med Australas 2015;27:6-10.

50. Jordan J, Elder J, Uijtdehaage S, Coates WC. Dual learning in an emergency medicine clerkship improves student performance. J Emerg Med 2016;50(471-6):e1-2.

51. Kellogg AR, Coute RA, Garra G. Diagnostic Reasoning for ST-segment elevation myocardial infarction (STEMI) interpretation is preserved despite fatigue. J Grad Med Educ 2015;7:27-31.

52. Kessler CS, Tadisina KK, Saks M, et al. The 5Cs of consultation: training medical students to communicate effectively in the emergency department. J Emerg Med 2015;49:713-21.

53. Kessler D, Pusic M, Chang TP, et al. Impact of just-intime and just-in-place simulation on intern success with infant lumbar puncture. Pediatrics 2015;135:e1237-46. 
54. Lamba S, Nagurka R, Offin M, Scott SR. Structured communication: teaching delivery of difficult news with simulated resuscitations in an emergency medicine clerkship. West J Emerg Med 2015;16:344-52.

55. Lawson LE, Musick D, Brewer K. Correlation of the National Emergency Medicine M4 Clerkship Examination with USMLE Examination Performance. West J Emerg Med 2015;16:1159-65.

56. Lehmann R, Thiessen C, Frick B, et al. Improving pediatric basic life support performance through blended learning with Web-based virtual patients: randomized controlled trial. J Med Internet Res 2015;17:e162.

57. Lorello GR, Hicks CM, Ahmed SA, Unger Z, Chandra D, Hayter MA. Mental practice: a simple tool to enhance team-based trauma resuscitation. CJEM 2016;18:136-42.

58. McGrath J, Kman N, Danforth D, et al. Virtual alternative to the oral examination for emergency medicine residents. West J Emerg Med 2015;16:336-43.

59. McNeil C, Muck A, McHugh P, Bebarta V, Adams B. Bedside rounds versus board rounds in an emergency department. Clin Teach 2015;12:94-8.

60. Reddy ST, Zegarek MH, Fromme HB, Ryan MS, Schumann SA, Harris IB. Barriers and facilitators to effective feedback: a qualitative analysis of data from multispecialty resident focus groups. J Grad Med Educ 2015;7:214-9.

61. Sabzghabaei A, Shojaee M, Alimohammadi H, Derakhshanfar H, Kashani P, Nassiriabrishamchi S. The effect of emergency department overcrowding on efficiency of emergency medicine residents' education. Emerg (Tehran) 2015;3:146-9.

62. Schott M, Kedia R, Promes SB, et al. Direct observation assessment of milestones: problems with reliability. West J Emerg Med 2015;16:871-6.

63. Sheng A, Eicken J, Lynn Horton C, Nadel E, Takayesu J. Interactive format is favoured in case conference. Clin Teach 2015;12:241-5.

64. Siegel NA, Kobayashi L, Dunbar-Viveiros JA, et al. In situ medical simulation investigation of emergency department procedural sedation with randomized trial of experimental bedside clinical process guidance intervention. Simul Healthc 2015;10:146-53.

65. Silverberg M, Weizberg M, Murano T, Smith JL, Burkhardt JC, Santen SA. What is the prevalence and success of remediation of emergency medicine residents? West J Emerg Med 2015;16:839-44.

66. Soares WE, Sohoni A, Hern HG, Wills CP, Alter HJ, Simon BC. Comparison of the multiple mini-interview with the traditional interview for U.S. emergency medicine residency applicants: a single-institution experience. Acad Med 2015;90:76-81.

67. Sricharoen P, Yuksen C, Sittichanbuncha Y, Sawanyawisuth $\mathrm{K}$. Teaching emergency medicine with workshops improved medical student satisfaction in emergency medicine education. Adv Med Educ Pract 2015;6:77-81.

68. Szulewski A, Roth N, Howes D. The use of task-evoked pupillary response as an objective measure of cognitive load in novices and trained physicians: a new tool for the assessment of expertise. Acad Med 2015;90:981-7.

69. Tan E, Brainard A, Larkin GL. Acceptability of the flipped classroom approach for in-house teaching in emergency medicine. Emerg Med Australas 2015;27:453-9.

70. Thoma B, Sanders JL, Lin M, Paterson QS, Steeg J, Chan TM. The social media index: measuring the impact of emergency medicine and critical care websites. West J Emerg Med 2015;16:242-9.

71. Valentin B, Grottke O, Skorning M, et al. Cortisol and alpha-amylase as stress response indicators during pre-hospital emergency medicine training with repetitive high-fidelity simulation and scenarios with standardized patients. Scand J Trauma Resusc Emerg Med 2015;23:31.

72. Wallenstein J, Ander D. Objective structured clinical examinations provide valid clinical skills assessment in emergency medicine education. West J Emerg Med 2015;16:121-6.

73. Wei G, Arya R, Ritz ZT, He AS, Ohman-Strickland PA, McCoy JV. How does emergency department crowding affect medical student test scores and clerkship evaluations? West J Emerg Med 2015;16:913-8.

74. Weizberg M, Smith JL, Murano T, Silverberg M, Santen SA. What does remediation and probation status mean? A survey of emergency medicine residency program directors. Acad Emerg Med 2015;22:113-6.

75. Wong AH, Wing L, Weiss B, Gang M. Coordinating a team response to behavioral emergencies in the emergency department: a simulation-enhanced interprofessional curriculum. West J Emerg Med 2015;16:859-65.

76. You-Ten KE, Wong C, Arzola C, et al. Role of contextualizing a crisis scenario on the performance of a cricothyrotomy procedural task. Can J Anaesth 2015;62:1104-13.

77. Zinns LE, O'Connell KJ, Mullan PC, Ryan LM, Wratney AT. National survey of pediatric emergency medicine fellows on debriefing after medical resuscitations. Pediatr Emerg Care 2015;31(551-4):1.

78. Reed DA, Cook DA, Beckman TJ, Levine RB, Kern DE, Wright SM. Association between funding and quality of published medical education research. JAMA 2007;298:1002-9.

79. Kirkpatrick DL, Kirkpatrick JD. Evaluating Training Programs: The Four Levels. [Sydney, NSW, Australia]; San Francisco, CA: ReadHowYouWant.com; Berrett-Koehler Publishers; 2010.

80. Nasca TJ, Philibert I, Brigham T, Flynn TC. The next GME accreditation system-rationale and benefits. N Engl J Med 2012;366:1051-6. 